\title{
Trajetória da formação de professores de Matemática no Instituto Superior de Ciências da Educação de Cabinda (1998-2009)
}

\author{
Inês Florinda Luís Buissa Baluta* \\ Maria Laura Magalhães Gomes ${ }^{* *}$
}

\section{Considerações iniciais}

No final da década de 1990, enquanto Angola passava por um período de grande instabilidade social, econômica e política devido à guerra civil, nas regióes mais a norte do país, Cabinda ${ }^{1}$ e Uíge, ${ }^{2}$ e na parte ocidental do país, Benguela ${ }^{3}$,

* Doutora em Educação pela Universidade Federal de Minas Gerais (UFMG) e professora do Departamento de Ensino e Investigação de Matemática do Instituto Superior de Ciências da Educação da Universidade Onze de Novembro (UON), Cabinda, Angola. E-mail: maniflor2002@yahoo.com.br.

** Doutora em Educação pela Universidade Estadual de Campinas (Unicamp) e professora do Departamento de Matemática e Programa de Pós-Graduação em Educação na Universidade Federal de Minas Gerais (UFMG). Bolsista de Produtividade do CNPq. E-mail: mlauramgomes@gmail.com.

1 Cabinda é uma das dezoito províncias de Angola e fica situada ao norte do país, com uma população estimada em 801.374 habitantes. É limitada ao norte pela República do Congo, ao sul e a leste pela República Democrática do Congo (anteriormente denominada Zaire) e a oeste pelo Oceano Atlântico. A sua superfície é aproximadamente de $7.283 \mathrm{~km}^{2}$. Cabinda está separada do resto do país a norte do rio Zaire por uma faixa de $60 \mathrm{~km}$, pertencente à República Democrática do Congo; por isso, é denominada um enclave. A província não tem ligação terrestre com o resto de Angola, a não ser através do Congo, e divide-se administrativamente em quatro municípios: Cabinda, Cacongo, Buco-Zau e Belize, sendo o município de Cabinda a capital da província. Antigamente a cidade de Cabinda era denominada Vila Amélia, tendo subido à categoria de cidade pelo Diploma Legislativo no 2757, de 28 de maio de 1956.

2 É uma província situada a norte de Angola, possui 16 municípios, e sua capital tem o nome semelhante ao da província, Uíge. Conta com uma população de 1.662.047 habitantes e uma área territorial de $58.698 \mathrm{~km}^{2}$.

3 Esta província está situada na parte oeste de Angola. Possui uma área de $39826 \mathrm{~km}^{2}$, com uma população de 606500 habitantes. 
tinha início a implantação do ensino superior. De acordo com Silva (2004), foram criados na década de noventa, os centros universitários de Benguela, com um núcleo de Direito e uma filial do Instituto Superior de Ciências da Educaçáo (ISCED), do Uíge, com um núcleo do ISCED, e de Cabinda, com um núcleo do ISCED, de Direito e de Economia. Por outro lado, apesar da criação desses centros universitários nos finais da década de 1990, o ensino superior em Angola já era uma realidade desde a década de 1960. Destarte, a formação em nível superior em Angola estava a cargo de instituiçóes e faculdades de ensino superior localizadas nas províncias de Lubango, Luanda e Huambo, enquadradas na Universidade Agostinho Neto (UAN), única no país até o ano de 2009. ${ }^{4}$ Esse fato mostra que o ensino superior na província de Cabinda, palco do nosso estudo, foi introduzido de modo tardio em relação a outras províncias de Angola.

Deste modo, a situação referenciada acima acarretava sérios constrangimentos para a província, porque, até ao final da década de 1990, as populaçôes da região da cidade de Cabinda, ao concluir o ensino médio, não tinham como realizar a formação superior nas suas localidades de origem por falta de instituiçóes vocacionadas para tal propósito. Os que tinham possibilidades financeiras deslocavam-se para o exterior da província ou do país, a fim de poderem dar continuidade aos estudos. Como consequência da falta de instituiçóes de ensino superior, ocorria um êxodo estudantil expressivo na cidade de Cabinda e em outras localidades do país.

O êxodo estudantil por falta de universidades, na maioria das províncias de Angola, fez com que muitos estudantes, após a conclusão de sua formação nas províncias onde estava instalado o ensino superior ou no exterior do país, não regressassem mais a suas localidades de origem. Esses profissionais recém-formados permaneciam nos locais da formação superior por terem constituído famílias ou terem o intuito de buscarem melhores possibilidades de exercício profissional. Com isso, surgiu no país o fenômeno denominado "fuga de cérebros" (Buissa, 2016). A falta de pessoal qualificado que pudesse assegurar o funcionamento do ensino superior era um problema grave para que a situação se modificasse nos lugares em que esse ensino ainda não estava presente.

Por conta da fuga de cérebros e da pressão social vivenciada em todo o país, fruto da falta de pessoal qualificado e capacitado para atuar nos mais diversos setores sediados nas diferentes províncias, no final da décadade 1990 começou

4 Decreto $^{\circ} 7 / 09$ de 12 de maio. Diário da República de Angola, I Série, nº 87 - Estabelece a reorganização da rede de instituições de ensino superior públicas, a criação de novas instituições de ensino superior e o redimensionamento da Universidade Agostinho Neto, revogando o Decreto n. ${ }^{\circ} 33 / 07$, de 24 de abril e o Decreto Executivo n. ${ }^{\circ}$ 60/ 01, de 5 de outubro. Disponível em: <http://www.pnfq.gov.ao/sites/ default/files/docs/decreto_7-09.pdf>. Acesso em: 22 jul. 2020. 
a se manifestar a intenção de se instalar o ensino superior em outras regióes de Angola. Assim, no seio da UAN, criou-se, em 1998, o Centro Universitário em Cabinda (CUC), e reinaugurou-se, em 1997, o Centro Universitário de Uíge, criado no ano de 1983. Assim sendo, "os centros universitários foram instalados um pouco por todo o País, para responder à enorme demanda juvenil e contribuir para o desenvolvimento das respectivas regióes" (Silva, 2004, p. 189).

Como referido anteriormente, o CUC começou com funcionamento das faculdades de Direito, de Economia e o ISCED. Das três unidades orgânicas, o ISCED é o único vocacionado à formação de professores. ${ }^{5}$ Esse instituto começou funcionando com os cursos de Ciências da Educação, opção Matemática, opção Psicologia, opção Pedagogia e opção História. Desde seu início, os quatro cursos formam professores de Matemática, Psicologia, Pedagogia e História, respectivamente, para atuarem no sistema de ensino angolano.

Nesse ínterim, com o objetivo de seguir a formação de professora, no ano de 2004 a primeira autora ingressou como estudante do curso de Ciências da Educação, opçáo Matemática, e seis anos depoiscomeçou a atuar como docente do curso em que se formou. Tendo em conta esse aspecto, reveste-se de especial relevância analisar o processo de formação de professores no curso de Ciências de Educação, opção Matemática.

Desta feita, para a realização deste estudo, foram, então, relevantes as posiçóes da primeira autora como ex-estudante e docente do curso, que se aliaram à análise de documentos escritos e de depoimentos orais de pessoas envolvidas no curso - docentes e ex-discentes - para que pudéssemos esboçar um quadro sobre o processo de formaçáa de professores de Matemática em nível superior na província de Cabinda. Os depoimentos orais foram produzidos a partir da metodologia da História Oral, considerando que ela é, "pois, sempre, um inventário de perspectivas irremediavelmente perpassado pela subjetividade, um desfile de memórias narradas, um bloco multifacetado de verdades enunciadas" (Garnica, 2010, p. 31).

Neste artigo, apresentamos parte dos resultados da tese de doutoramento da primeira autora, que buscou responder à questão central "Como se deram o processo de criação e a trajetória do curso de Ciências da Educação, opção Matemática, do Instituto Superior de Ciências da Educação (ISCED) de Cabinda no recorte temporal de 1998 a 2009?”.

No entanto, o objetivo da investigação foi a construção de narrativas históricas por meio da História Oral sobre o processo de formação de professores de Matemática em Cabinda. Cabe salientar que a História Oral não foi usada

Decreto no 95/80 de 30 de agosto. Diário da República Popular de Angola, I Série, n. 206 - Cria o Instituto Superior de Ciências da Educação (ISCED) do Lubango. 
para preencher as lacunas que os documentos existentes deixaram, mas por ela ser de grande potencial para produzir outras versóes históricas.

\section{Aspectos teórico-metodológicos: a história oral como método de pesquisa}

Neste estudo, como mencionado, as narrativas orais não se constituíram como única fonte para a compreensão do tema de pesquisa, já que recorremos também a documentos legais, tais como: decretos, atas de reunióes, grades curriculares, programas, lista dos alunos da primeira turma, monografias de conclusão de curso, entre outros. Desse modo, buscamos reconstruir a história da formação de professores fazendo articulação/diálogo entre os depoimentos orais e documentos existentes na instituição, com o fito de ampliar as possibilidades da investigação. Merece ser destacado que os depoimentos orais foram produzidos através de entrevistas em História Oral, com sujeitos ligados ao curso de Matemática. Assim, entendemos a História Oral como:

[...] um método de pesquisa (histórica, antropológica, sociológica etc.) que privilegia a realização de entrevistas com pessoas que participaram de, ou testemunharam, acontecimentos, conjunturas, visóes de mundo, como forma de se aproximar do objecto de estudo. [...] Trata-se de estudar acontecimentos históricos, instituiçóes, grupos sociais, categorias profissionais, movimentos, conjunturas etc. à luz de depoimentos de pessoas que deles participaram ou os testemunharam. (Alberti, 2005, p. 18).

Nessa perspectiva, a História Oral constitui-se como uma metodologia em que os sujeitos constroem várias versóes sobre determinados fatos e acontecimentos. Em vista disso, a partir da escuta dos relatos orais de nossos depoentes, objetivamos o resgate de informaçóes relacionadas à suas histórias de vida, visóes de mundo, vivências e experiências pessoais, sociais e profissionais, ou seja, suas memórias individuais e coletivas que nos revelam aspectos referentes ao objeto de estudo.É imprescindível assinalarque, ao narrar sobre determinado fato, a memória do sujeito não consegue trazer à tonatudo aquilo que se passou, mas acreditamos que ela é capaz de atingir aspectos que ficaram despercebidos nos registros. No entanto, o uso da memória na História Oral tem sido alvo de crítica por parte de alguns historiadores, visto que eles as rotulam como difusas e não confiáveis (Almeida, 2009; Lozano, 2006; Thomson, 2000; Thomson, Frisch, Hamilton, 2006). 
Embora a natureza da memória seja falha, ela permite a reconstrução do passado, tendo em conta os interesses e visóes do mundo assentadas no presente, isto é, "a memória é uma construção sobre o passado, atualizada e renovada no tempo presente" (Delgado, 2010, p. 9). A memória é também feita de lembranças, silêncios, apagamentos e esquecimentos, e traz à tona aspectos significativos relacionados aos interesses e necessidades do momento, ela é uma "teia de subjetividades" (Almeida, 2009, p. 215).

No trabalho com História Oral, a subjetividade possibilita ao narrador a construção de significados, crenças, representaçôes, conexôes, juízos de valor sobre o passado. Para Thompson (1998), toda fonte histórica derivada da percepção humana é subjetiva, mas apenas a fonte oral nos permite desafiar essa subjetividade: descolar as camadas de memória, cavar fundo em suas sombras, na expectativa de atingir a verdade oculta. Portanto, a memória e a subjetividade constituem-se em fortaleza para a História Oral porque permitem compreender os fatos passados com grande natureza de detalhes (Buissa, 2016, p. 35).

Queremos sublinhar que se entende narrativa "como a organizaçáo dos acontecimentos de acordo com determinado sentido que lhes é conferido" (Alberti, 2004, p. 92).

Para a produção de narrativas, os colaboradores cujos relatos usamos neste artigo foram escolhidos por terem sido professores e ex-estudantes do curso de formação de professores de Matemática e passamos a nomeá-los a seguir: Domingos Kimpolo Nzau, José Alfredo Bassanza, Lucas Raposo Ramos, Nlandu Balenda, David Macaia Bumba, Faustino Mombo Kuabi, José Soma Daniel, Estevão Gomes, Nicolau Bifica, António Teodoro Matombe.

Desse modo, apresentamos falas de 10 entrevistas, nas quais, no primeiro encontro, foi necessário entregar ao entrevistado o roteiro da entrevista, para situáloacerca da intenção do estudo. Todas as entrevistas foram realizadas no ano de 2013. As entrevistas foram transcritas e em seguida realizamos suas textualizaçóes retirando os vícios de linguagem. Uma vez feita as textualizaçóes, elas foram entregues aos depoentes para que pudessem confirmar ou alterar qualquer parte, de acordo com o que desejassem.

Enquanto líamos as narrativas, nos deparamos com múltiplas lembranças sobre experiências de vida, visões de mundo, sentimentos, emoções, angústias, desejos, projetos, frustraçóes, ansiedades, sonhos náo realizados, encantos, desencantos, descobertas, expectativas de vida, satisfação de dever cumprido, lembranças sobre o passado, emitidos pelos sujeitos no presente. No entanto, essas "lembranças, quase sempre, passam pelo crivo dos valores atuais, resultantes da inter-relação sociedade-indivíduo, que determinam um tipo de discurso, de prática, de experiência" (Garnica; Souza, 2012, p. 105). Dessa forma, na elaboração 
desse texto, demos especial atenção ao que os nossos colaboradores lembraram sobre a criação do curso, as carências observadas nele e o funcionamento das propostas curriculares.

\section{O surgimento do curso de formação de professores de Matemática a partir da criação do ensino superior em Cabinda}

Como salientado no início deste texto, no final da década de 1990, antes da implantação do ensino superior em Cabinda, alguns indivíduos que terminavam os seus estudos em nível médio eram obrigados a se deslocar para as províncias onde o ensino superior estava instalado (Huila, Huambo, Luanda) ou para o exterior do país, a fim de dar continuidade à formaçáo superior. $\mathrm{O}$ ex-aluno, hoje professor, David Macaia Bumba (2013), teceu alguns comentários sobre o assunto: "[...] porquanto muito boa gente teve que se deslocar fora da província, uns fora do país, para aumentar o seu nível acadêmico".

A busca pela formação superior fora da província de Cabinda implicava avultados custos financeiros e só era possível a pessoas com boas condiçóes financeiras, capazes de suportar os estudos ou a quem tivesse a oportunidade de ser contemplado com bolsa de estudos paga pelo governo ${ }^{6}$ ou por alguma empresa que presta serviços sociais em Angola. ${ }^{7}$ O professor Faustino Kuabi e o ex-aluno Nicolau Bifica relataram sobre esse fato:

Havia muitos alunos que, depois de concluírem o ensino médio, não sabiam aonde ir para dar continuidade aos estudos. Nem todos tinham recurso para ir ao Lubango, a Luanda ou fora do país. (Faustino Mombo Kuabi, 2013).

No ano de 1995, concluí a décima segunda classe, na opção Matemática e Física, na mesma instituição. Fiquei outra vez estagnado porque, até ao ano de 1995, não se falava de expansão universitária em Cabinda. Ficamos parados à espera, mas os demais colegas, por esforço pessoal, tiveram que abandonar a província e ir ao encontro do nível superior. E nós, que

6 Em Angola, algumas bolsas são oferecidas pelo Instituto Nacional de Gestão de Bolsas de Estudos (INAGBE) e outras pelo Ministério dos Petróleos.

7 Cabinda Gulf Oil Company Limited (CABGOC), TOTAL S. A, British Petroleum (BP), SONANGOL são empresas do ramo petrolífero que subsidiam bolsas de estudo interna e externa para candidatos por meio de exames. 
carecíamos de condições econômicas, tivemos que ficar cá na esperança da instalação do ensino superior na província. (Nicolau Bifica, 2013).

Com a ausência de instituições vocacionadas à formação superior na província de Cabinda houve um expressivo êxodo estudantil, ocasionando por vezes a fuga de capital humano. No entanto, a fuga de cérebros acarretava consequências financeiras, econômicas e sociais para a província. Por conseguinte, a perda de indivíduos com aptidóes técnicas, científicas por conta do êxodo estudantil, o aumento de técnicos médios e a falta de instituiçóes de ensino superior em Cabinda não permitiam o desenvolvimento adequado dos vários setores econômicos e sociais sediados nela. Em virtude disso, era necessário qualificar os quadros com nível superior. Destarte, para que o ensino superior se tornasse realidade em Cabinda, foi necessária a criação de uma comissão encarregada a tal propósito, assim como frisou o professor Bassanza:

[...] mas tendo em conta a pressão social e a própria vontade política naquela altura, em função disso surgiu aquilo que nós chamamos de COPIESCA Comissão Provincial Instaladora do Ensino Superior em Cabinda. A comissão surgiu por um despacho exarado por Sua Excelência na altura, o governador Amaro Tati, no ano de 1996, coordenada pelo Doutor Domingos Kimpolo Nzau, e tendo como coordenador adjunto o Doutor Feliciano Lopes Toco, com a supervisão, é claro, do governador e do vice-governador, o Doutor Miguel dos Santos Oliveira. (José Alfredo Bassanza, 2013).

Essa comissão elaborou um projeto no qual constavam estratégias para a criação do ensino superior em Cabinda. $\mathrm{O}$ mesmo projeto proposto com a nota n. ${ }^{\circ}$ 000420/80/GAB.D/DPEC/96, de 17 de outubro de 1996, foi enviado ao Ministério da Educação (MED) sediado em Luanda ${ }^{8}$ e teve o parecer positivo por meio do Despacho de 27 de dezembro de 1996, do ex-ministro da Educação Dr. António Burity da Silva Neto, ${ }^{9}$ que autorizou a abertura do CUC. A informaçáo acerca desse despacho foi obtida por meio da nota $n^{\circ}$ 0049/4a/4.3/RE/96, a 14 de janeiro de 1997 (Buissa, 2016).

Aprovada a criação do CUC, os membros da comissão trabalharam com afinco a fim de criar as condiçóes para o início do funcionamento do ensino

8 Anteriormente os assuntos relacionados ao ensino superior eram tutelados pelo Ministério da Educação (MED) Atualmente' o Ministério do Ensino Superior' Ciência' Tecnologia e Inovação (MESCTI) é quem tutela o ensino superior

9 Foi nomeado ao cargo de ministro da Educação pela primeira vez pelo Decreto Presidencial n. ${ }^{0}$ 15/91, de 12 de janeiro, e o exerceu até 20 de novembro de 1992. Ao abrigo do Decreto Presidencial n. 25/96 de 7 de junho, foi nomeado pela segunda vez para exercer a função de ministro da Educação. 
superior. Mas apesar de o CUC ter sido criado através do despacho exarado pelo ex-ministro da Educação, visto que competia ao MED aprovar a criação de faculdades, institutos superiores ou academias, bem como de cursos, cabia à UAN a responsabilidade de organizar os cursos criados pelo MED. ${ }^{10}$ Essa cláusula impossibilitou que o centro começasse a funcionar assim que o despacho fosse lavrado, visto que o ex-reitor da UAN, José Luís Guerra Marques, argumentou que a província de Cabinda não apresentava condiçôes condignas para a instalação do ensino superior e que todas as faculdades na UAN estavam vivendo problemas sérios de várias ordens (UAN, 1998, p. 2).

Entretanto, com a mudança de direção na UAN, ${ }^{11}$ deslocou-se para a cidade de Cabinda, nos meados do ano de 1998, uma comissão da reitoria com o fito de averiguar as condiçóes que haviam sido criadas pela Comissão Provincial Instaladora do Ensino Superior em Cabinda (COPIESCA) e efetuar as negociaçôes para o começo das atividades do CUC. Em Cabinda, a delegação se reuniu com os membros da COPIESCA e alguns representantes do governo provincial de Cabinda. O professor Estevão Gomes relatou alguns fatos da reunião:

Em 1997, concorremos para o ISCED, mas antes disso já fazíamos trabalhos de criação de condiçóes para criação do Centro Universitário de Cabinda. Não foi uma tarefa fácil, foi muito difícil, porque encontramos muitos obstáculos. O governo da província estava disposto a ajudar, mas o problema estava a nível da reitoria da Universidade Agostinho Neto. Com o aval do ex-ministro da Educação, António Burity da Silva, deslocou-se uma delegação da reitoria da Universidade Agostinho Neto a Cabinda a fim de se discutir seriamente acerca do problema. A reunião começou às 20 horas e terminou somente às 4 horas da madrugada. Havia duas alas, uma estava a favor e a outra estava contra, incluindo a própria reitora daquela época, Laurinda Hoygaard. Inicialmente a reunião estava sendo orientada pelo vice-governador, Sr. Martins da Cruz Nombo. Quando era 1 hora da madrugada, o Sr. Martins da Cruz Nombo foi obrigado a chamar o governador, na época, José Amaro Tati. Os problemas que se colocavam eram a falta de docentes, a falta de uma verba a nível da reitoria que pudesse suportar as deslocaçôes, a estadia, a alimentação dos professores itinerantes. Depois de grandes discussóes, o ex-governador, José Amaro Tati, teve que disponibilizar um milhão de dólares por mês para ultrapassar a situação. A partir dessa condição, a reitora, naquele momento, aceitou a implantação do

10 Conforme o Decreto n 2/95 de 24 de março. Diário da República de Angola, I Série, n. ${ }^{\circ} 12$ - Aprova o Estatuto Orgânico da Universidade Agostinho Neto e revoga o Decreto n. ${ }^{\circ} 17 / 89$ de 13 de maio.

11 Foi nomeada a Doutora Laurinda Hoygaard como nova reitora da UAN. 
Centro Universitário em Cabinda. O centro começou a funcionar com três núcleos: o núcleo do ISCED, onúcleo de Direito e o núcleo de Economia. Quais foram os primeiros cursos? Para o ISCED, o curso de Matemática, o curso de Psicologia, História e Pedagogia. Para a Faculdade de Economia, o curso de Economia Geral e o núcleo de Direito, o curso de Direito. (Estevão Gomes, 2013).

Diante do que foi exposto, verificamos que, em decorrência das negociaçóes mantidas no encontro entre a comissáo da reitoria, os membros da COPIESCA e do governo provincial de Cabinda, foi assinado um protocolo para a abertura do CUC. Tal como foi assinalado pelo professor Esteváo Gomes, o centro universitário começou a funcionar com três núcleos ligados à UAN com sede em Luanda: núcleo da Faculdade de Direito, com o curso de Direito; núcleo da Faculdade de Economia, com o curso de Economia; núcleo do ISCED, com os cursos de Ciências da Educação, opção História, opção Matemática, opção Psicologia e opção Pedagogia.

Neste ínterim, dos três núcleos implementados no CUC, o núcleo do ISCED é o mais próximo do nosso objeto de estudo. Esse núcleo pertence ao ISCED de Luanda e tem por objetivo a formação de professores, gestores e pesquisadores. ${ }^{12}$ Em sua narrativa, o professor Estevão Gomes também discorreu acerca de um dos objetivos do ISCED.

Sabe-se que o ISCED é uma instituição superior para formação de professores para o ensino médio a fim de minimizar as carências vivenciadas neste ensino.

A partir dos relatos dos entrevistados, verificamos que o Núcleo do ISCED começou a funcionar com quatro cursos. Dos quatro cursos, o curso de Ciências da Educação, opção Matemática, constitui o nosso objeto de investigação. Em conformidade com as narrativas dos depoentes e os documentos escritos, ficou evidente que o curso de formação de professores de Matemática na província de Cabinda surgiu a partir da brecha da criação do CUC. O objetivo desse curso foi descrito pelo professor Bassanza:

O objetivo fundamental do curso de Matemática é prepararmos professores, porque o Instituto Superior de Ciências da Educação é a instituição vocacionada para preparação de professores, portanto o objetivo do curso é preparamos professores para poderem ministrar aulas de Matemática nas escolas médias, que atualmente são escolas do ensino secundário do segundo ciclo. Este foi o objetivo fundamental e primordial, para além de realizar outras atividades, mas a principal é preparar professores com o objetivo de 
administrar aulas de Matemática nos institutos médios sediados na nossa província. (José Alfredo Bassanza, 2013).

$\mathrm{Na}$ passagem citada acima, o depoente revela que o curso de Ciências da Educação, opção Matemática, para além de realizar outras atividades, também forma professores. As atividades/formaçóes que o professor não citou são as mesmas realizadas em todos os cursos ministrados no ISCED, que são a formação de gestores e pesquisadores. No caso do curso investigado, seu objetivo é a formação de professores, gestores e pesquisadores na área de Matemática.

$\mathrm{O}$ ingresso ao curso de Ciências da Educação, opção Matemática, tem sido feito por meio de exame de acesso realizado por candidatos que tenham concluído a $12^{\text {a }}$ classe em qualquer instituição do ensino médio. Quanto ao primeiro "exame de admissão, vinham perguntas sobre Matemática e cultura geral” (António Teodoro Matombe, 2013). Atualmente, as provas ainda são preparadas com uma parte de conhecimentos gerais e outra de conhecimentos relacionados à Matemática. O professor Balenda mostrou como é/era feito o ingresso na instituição:

Bom, o ingresso de estudantes no Instituto Superior de Ciências da Educação faz-se sempre por meio de exame de acesso, esta é a prática em Angola. $\mathrm{O}$ ingresso para o ensino superior processa-se via exames de acesso. Determinamos cada ano, os números clausus ${ }^{13}$ de quantos estudantes são necessários para cada opção, isto de acordo com a capacidade de recepção (acolhimento das salas de aulas disponíveis). Sabes que o ISCED até agora não tem instalaçóes próprias, aquele espaço onde funciona pertence ao Instituto Médio de Economia (IMEC). Os candidatos com maiores resultados nos exames são selecionados, os demais esperam outras oportunidades até conseguirem...! (Nlandu Balenda, 2013).

Nos últimos anos, com o aumento da demanda no acesso ao ensino superior, somente os candidatos com maiores resultados são selecionados, tal como evidenciado no trecho acima. Essa particularidade náo era observada nos primeiros anos do curso, já que havia poucos candidatos, sendo que eram selecionadas até as notas inferiores a 10 valores. Podemos verificar algumas narrativas sobre o assunto:

13 Lança-se o concurso para os candidatos ocuparem as vagas, isto é, os melhores. O número clausus depende da capacidade das salas e nunca ultrapassa 50 alunos em cada sala de aula. Cada opção podia ter duas turmas com 50 alunos cada, isto é, 100 estudantes por opção. O curso de Matemática era excepção, porque nunca chegava aos 50 alunos por turma, por ser um curso "difícil". 
Quando entramos, poucos alunos tiveram média positiva nos exames de ingresso; então, para o preenchimento de vagas, foram repescando as negativas mais altas. (Lucas Raposo Ramos, 2013).

[...] e aqueles que tiveram uma nota baixa tiveram que ser admitidos, isso para motivar e procurarmos ter um número satisfatório para criarmos uma turma. (Nicolau Bifica, 2013).

Um ano depois, o curso ainda vivenciava a mesma situação quanto ao acesso de candidatos.

Quando eu fiz a inscrição para ingressar no curso de Matemática, no ano 2000, havia 40 vagas para licenciatura em Matemática e éramos 40 candidatos; quer dizer que até o estudante que teve a mínima nota também entrou. (José Soma Daniel, 2013).

Pouco tempo depois da realização dos exames de acesso, as aulas tiveram oseu início. Porém, os problemas levantados na reunião que possibilitou a abertura do CUC começaram a ser vivenciados pelo curso no começo do seu funcionamento, tal como mostraremos a seguir.

\section{As condições de funcionamento nos primeiros anos do curso de formação de professores de Matemática}

Como um dos quatro cursos inseridos no núcleo do ISCED de Luanda em Cabinda, o curso de Ciências da Educação, opção Matemática, vivenciou os mesmos problemas que todos os cursos estavam enfrentando, "se prendiam na carência de cobertura docente, na precária infraestrutura, na falta de bibliografia, na incerteza de funcionamento, nos livros e programas desatualizados, na mobilidade docente e discente" (Buissa, 2016, p. 182-183). Destacamos o trecho do professor José Bassanza que nos permite conhecer essa realidade:

A primeira carência era a questão relacionada com o corpo docente, tivemos problemas sérios com o corpo docente. Não tínhamos corpo docente à altura, e local para administrar as aulas de Matemática a nível da província de Cabinda. Com a demanda, o número de salas em termo de infraestruturas, o número de salas previstas para formação a nível de ciências exatas era muito reduzido. Para além da turma do curso de Matemática, tínhamos também 
as turmas das outras áreas de formação, tais como a do curso de Psicologia, a do curso de Pedagogia e a turma da Faculdade de Economia. Portanto, em termos de infraestruturas, começamos a viver a carência de salas, e isto levou com que o governo local evidenciasse esforço para encontrar novos espaços para o funcionamento do ISCED. Foi quando o ISCED passou a funcionar em dois pavilhóes das instalaçóes do Instituto Médio de Economia (IMEC). Lembrando que o ISCED, a Faculdade de Economia e a Faculdade de Direito começaram a funcionar nas instalaçóes da antiga escola primária, Ho Chi Minh, onde funciona atualmente a reitoria da Universidade Onze de Novembro. Dificuldades, tal como acontece em toda parte do mundo, são várias; por isso, enumero também a carência de bibliografia, de material de trabalho. Atualmente quando falamos de Matemática, não temos nesse momento uma biblioteca, material didático, bibliografia atualizada, uma sala de informática especificamente para o curso de Matemática. (José Alfredo Bassanza, 2013).

O relato acima nos mostra que uma das carências que o curso estava enfrentando era a falta de professores em quantidade e em qualidade, pois apesar de existirem professores locais, eles não possuíam experiência suficiente para lecionar no ensino superior. Para superar a escassez de docentes, o centro teve de contar com a ajuda de professores provenientes dos ISCEDs instalados nas províncias de Luanda e Lubango. O professor Kimpolo Nzau nos leva a compreender mais sobre o assunto:

Primeiro é que não tivemos docentes à altura, e era necessário fazermos acordos com instituiçôes de Luanda que nos pudessem ajudar no sentido de irem dando esta ou aquela cadeira. $\mathrm{E}$ as coisas não foram fáceis, porque tínhamos de pagar-lhes transporte, tínhamos que pagar alimentação, tínhamos que pagar os salários, tínhamos que pagar uma série de coisas e não é como agora que temos portanto a TAAG ${ }^{14}$ à disposição; naquela altura não era fácil, portanto, viajar. ${ }^{15}$ As condiçóes de habitabilidade, de alojamento não eram boas e muito menos, portanto, de uma alimentação que digamos assim eficiente. (Domingos Kimpolo Nzau, 2013).

Pela dificuldade com transporte e por conta de seus encargos laborais, os docentes que provinhamde Luanda lecionavam aulas de 15 em 15 dias. A

\footnotetext{
14 Linhas Aéreas de Angola, empresa pública de transporte aéreo.

15 Não era fácil porque Cabinda se situa num enclave, e para se deslocar de Cabinda para Luanda, a população tem de fazer uso de barco ou de avião.
} 
narrativa do ex-aluno Lucas Raposo é marcada por essas lembranças:

No início tinha dois grupos de professores. Havia professores estagiários locais e havia os professores que vinham de Luanda, que nós chamávamos de regentes. A maior parte das disciplinas ligadas à área de Matemática eram leccionadas pelos professores regentes que vinham de Luanda. Eles vinham de 15 em 15 dias, davam um lote de conteúdo, e os nossos estagiários tinham como missão ir superando as nossas dúvidas e trabalhando conosco. Mas, conforme disse anteriormente, alguns estagiários cá locais não conseguiram fazer a sua parte, não sei se é por falta de capacidade ou mesmo por preguiça. (Lucas Raposo Ramos, 2013).

Nesse sentido, a escassez de docentes ocasionou algumas consequências, assim como descreveu o professor Balenda:

O primeiro ano académico de todos os núcleos durou 16 meses, por falta de docentes. Havia indivíduos matriculados que nunca podiam transitar para o segundo ano por falta de docentes. Nossos colegas de Luanda muitas vezes não vinham porque não havia forma de lhes pagar corretamente. (Nlandu Balenda, 2013).

A falta de decisão no curso quanto ao corpo docente levou a direção a optar pela cooperação cubana, tal como ficou evidente na narrativa do professor Kimpolo Nzau:

A cooperação sempre foi necessária, não só no domínio de ensino, mas em todos os domínios. No domínio educativo, contamos com o proveito dos professores cubanos e temos uma cooperação profícua e frutífera. Os outros cooperantes são muito exigentes em todos os sentidos. Ontem, por andarmos em guerra, poucos estavam interessados em viver no ambiente de guerra, porque no ambiente de guerra o dia de amanhã era sempre uma incerteza. Os cubanos desde a primeira hora nos apoiaram nesse sentido, não só na guerra em que estávamos mergulhados, mas desde o tempo colonial, desde o jugo colonial. Por isso, achamos que seria necessário continuarmos com a colaboração em todos os domínios. [...] O governo cubano aceitou a cooperação e nunca tivemos dificuldades em lidar com eles; embora falassem a língua espanhola, entendemos $90 \%$ da sua explanação. (Domingos Kimpolo Nzau, 2013).

Outra dificuldade que o curso estava enfrentando era a carência acentuada 
de bibliografia. Segundo os depoentes, não havia biblioteca nas instalações do ISCED. Por isso, alguns recorriam à biblioteca municipal para consultar livros. Outros usavam seus livros obtidos enquanto eram estudantes no exterior da província ou do país. Os professores Nlandu Balenda e Faustino Kuabi falaram de suas experiências relacionadas à bibliografia:

Não havia biblioteca, nem a internet; naquele momento não tinha espaço para tal. O que fizemos, cada um de nós com base na sua experiência na vida escolar, buscava o livro dele, metia lá para ser consultado. No meu caso, perdi mais de quinze livros, para não falar do meu colega Marcos Miguel Zinga Nessengue, que tinha o hábito de colocar livros na sala de leitura. O ISCED até hoje não tem biblioteca, o que temos é sala de leitura; temos colocado algumas migalhas que conseguimos aí fora. Mas, estamos a trabalhar para constituir uma biblioteca de verdade. (Nlandu Balenda, 2013).

Em princípio, aqui temos problemas de bibliotecas; praticamente, o ISCED, ou melhor, o Centro Universitário de Cabinda não tinha biblioteca alguma. A nossa sorte, isto para nós que viemos de Cuba, é a vantagem de termos trazido muitos livros; isto nos ajudou muito. Existia a Biblioteca Municipal de Cabinda, me recordo na altura, de vez em quando ia para lá, mas não me serviu muito, porque já tinha muitos livros trazidos de Cuba. (Faustino Mombo Kuabi, 2013).

As consideraçóes tecidas acima pelos depoentes nos possibilitaram constatar que no curso de formação de professores de Matemática havia uma gritante escassez de professores em qualidade e quantidade. A instituição onde o curso era/é ministrado não possui instalaçôes próprias até o presente momento. No começo do funcionamento da instituiçáo, as aulas dos cursos eram dadas na antiga escola Ho Chi Minh. Depois se instalaram na parte dos fundos do edifício pertencente ao IMEC. Não havia bibliotecas em condiçóes para a pesquisa por parte dos estudantes, nem bibliografias para auxiliar os docentes na preparação das aulas. Com tanta carência observada, como eram definidas as linhas orientadoras do curso? É sobre essa questão que trataremos na próxima seção.

\section{Propostas curriculares: as grades curriculares que vigoraram no curso}

A partir da documentação e dos relatos orais, verificamos que a grade curricular e os programas usados nos primeiros anos do curso sáo os mesmos que estavam sendo usados pelos primeiros cursos de formação de professores 
de Matemática existentes nos ISCEDs de Luanda, Lubango e Huambo. Com o advento das novas tecnologias, foram acrescidas à grade curricular algumas disciplinas relacionadas às novas tecnologias, tal como relatado pelo professor Kimpolo Nzau:

Bom, a estrutura curricular e os programas não se diferenciaram daquela estrutura curricular e do programa escolar que tivemos nos primeiros anos da criação do ISCED do Lubango. [...] Mas aquela estrutura antiga pouco ou nada se alterou. Foi também incluindo as novas tecnologias e novas perspectivas do ensino, isto no âmbito dos programas, e não no próprio plano de estudos. (Domingos Kimpolo Nzau, 2013).

No começo do curso, o plano curricular estava organizado em cinco anos e oferecia disciplinas ligadas às Ciências Exatas e de natureza psicopedagógica. Constavam também as disciplinas Filosofia Geral e História de Angola. No trecho abaixo, o professor David Macaia destaca algumas das disciplinas que figuravam na grade curricular:

Um conjunto de disciplinas; tivemos, por exemplo, a Análise Matemática I e II, a Geometria Analítica, a Pedagogia, a Didática da Matemática, Metodologia de Ensino da Matemática, a Mecânica, as Álgebras Linear e Superior, a Análise Numérica, a Topologia, a cadeira de Informática, enfim. Esses conjuntos de disciplinas que faziam parte do nosso currículo nos potenciaram, nos tornaram hoje o que somos, e nos permitem hoje darmos sequência da nossa formação no ramo. (David Macaia Bumba, 2013).

Essas são algumas das disciplinas que faziam parte da primeira grade curricular utilizada no curso, ${ }^{16}$ até ao ano 2004. Algumas disciplinas presentes no plano curricular tinham regime de procedência (pré-requisito), isto é, não era permitido se matricular no outro semestre numa determinada disciplina, enquanto não fosse cursada com aprovação uma disciplina anterior. Por exemplo, a inscrição em Análise Matemática II dependia da aprovação em Análise Matemática I. De acordo com o relato do depoente e a partir do estudo das grades curriculares do curso, verificamos que era dada maior ênfase as disciplinas matemáticas em relação às pedagógicas.

A grade curricular acima referida funcionou de 1998 até 2004, ano em que se implantou o novo currículo, fruto da reforma realizada em toda a UAN (Buissa, 2016). Com essa reforma, a duração do curso passou de cinco para quatro anos, e

16 Vide grades curriculares completa em Buissa (2016, p. 197-198; p. 202-204). 
ela teve por objetivos a revisão, o diagnóstico, a atualização e a padronização dos currículos e programas de todas as faculdades, institutos e escolas superiores da universidade. Podemos ver abaixo um trecho da narrativa do professor Estevão Gomes sobre a reforma:

Os cursos tinham a duração de cinco anos; com a reforma curricular os cursos passaram a durar quatro anos. Em algumas disciplinas foi reduzida a sua carga horária e isso fez com que o tempo de duração fosse também reduzido. (Estevão Gomes, 2013).

Inferimos, a partir dos relatos, que as reformas curriculares são elaboradas para responder às demandas sociais, políticas, econômicas e culturais do momento. No entanto, elas não são estáticas e podem sofrer alterações conforme os objetivos que se deseja alcançar num determinado momento.

\section{Memórias dos primeiros alunos do curso de formação de professores de Matemática}

Segundo os nossos entrevistados, a maioria dos primeiros estudantes era natural da província de Cabinda, e outros eram naturais de outros pontos do país. Os primeiros estudantes também tinham idades e perfis diversificados. Suas idades estavam compreendidas entre os 25 e os 40 anos. A maior parte desses ex-estudantes do curso eram/são professores de Matemática nas escolas sediadas na província. Mas também havia policiais, bancários, militares, técnicos de saúde e operadores de empresas petrolíferas. Por conta de suas ocupaçóes, por vezes, o horário escolar coincidia com o horário do trabalho. O ex-aluno Lucas Raposo salientou sobre esse assunto:

Os horários não eram compatíveis, porque havia estudantes que estudavam de manhã e trabalhavam no mesmo período em que estudavam. Mas esses estudantes trocavam de horário com alguns colegas de trabalho. (Lucas Raposo Ramos, 2013).

Para além da incompatibilidade do horário das aulas, o modo como as aulas eram ministradas e as dificuldades apresentadas pelos professores efetivos do curso deixaram marcas na trajetória acadêmica de alguns estudantes. Lucas Raposo teceu algumas consideraçôes sobre a época: 
Há lembranças positivas e lembranças negativas. As negativas são acerca daqueles docentes que apareceram no segundo, principalmente no terceiro ano, alguns locais. Esses professores que trabalhavam conosco, alguns no ensino médio, com licenciatura feita, postos para dar aulas no terceiro ano do curso de Ciências da Educação, opção Matemática, muitos não conseguiram concretizar o nosso objetivo. Muitos destes professores começaram a lecionar, mas não concluíram. Até me recordo dum professor assistente da disciplina Análise Matemática III; o docente regente que vinha de Luanda tinha deixado umprograma de seis capítulos e o material para o assistente dar continuidade às aulas, mas, durante o semestre, o professor assistente leccionou apenas um capítulo. Quando o professor regente chegou, teve que anular a cadeira durante aquele ano. Foram lembranças tão tristes para nós! Quanto às lembranças positivas, tivemos alguns professores angolanos competentes; posso citar um deles, que é o professor Faustino - este foi um dos professores que me marcou muito, além dos cooperantes cubanos. (Lucas Raposo Ramos, 2013).

Nesse trecho, o ex-aluno relembrou com satisfação um professor angolano que marcou a sua trajetória acadêmica. Na narrativa abaixo, o ex-aluno David Macaia mostrou seu descontentamento quanto à modalidade em que as aulas eram ministradas nos primeiros anos do curso em que se formou:

Lembro-me com insatisfação, porque não eram normais as condições a que estávamos sujeitos, fazer prova de manhá, recurso de noite, exame, enfim, tudo ao mesmo dia; éramos autênticos mercenários. [...] Já o dissemos há bem pouco tempo que uma cadeira de Análise, por exemplo, um conteúdo para um ano letivo era dado em um mês, isso não é normal. Deves calcular o quão foi sofrível para todos os compatriotas de luta da nossa época ter que eliminar essas cadeiras e se apropriar dos conhecimentos com zelo, mas não foi fácil, de maneira que podemos afirmar, sem medo de errar, que não começaram da melhor forma, porque uma coisa é ter o professor vinte quatro sobre vinte quatro e outra coisa é ter o professor que vem uma semana e volta daqui a um mês. (David Macaia Bumba, 2013).

Para as aulas da disciplina Análise Matemática, o ex-aluno Lucas Raposo referiu que usavam o livro de Nikolai Piskounov. Provavelmente o livro fazia parte da biblioteca pessoal do colaborador, pois a instituição não possuía biblioteca.

Nós, naquela altura, fazíamos buscas em alguns livros como o de Análise Matemática I, II e III, de Piskounov, mas a instituição não tinha biblioteca. 
O colega que tivesse um livro emprestava para os colegas tirarem cópias. Naquela altura a internet também não era tão usada. Então nós fomos encontrando dificuldades em termos de bibliografia. (Lucas Raposo Ramos, 2013).

Para além da carência de bibliográfica, no trecho acima, o ex-aluno acresceu que não faziam uso de internet. Essa fala foi corroborada pelo ex-aluno Nicolau Bifica (2013), que acrescentou, "naquela altura nem tal internet ninguém entendia o que significava”.

Para as aulas de informática, nem todos os estudantes poderiam fazer uso do computador ao mesmo tempo, mostrando que também havia precariedade de equipamentos, tal como narrado pelo ex-aluno Lucas Raposo: "Havia uma sala de informática que dava jeito. Tínhamos uma sala de informática, mas era necessário subdividir a turma em dois grupos, porque os computadores náo eram suficientes para todos" (Lucas Raposo Ramos, 2013).

Apesar das muitas dificuldades e carências vividas no curso, o ex-aluno José Soma louvou a criação do ensino superior na província e relatou que ter cursado o ensino superior lhe possibilitou a recepção de um salário aceitável:

Foi uma mais valia para Cabinda, hoje em dia já somos licenciados, graças à implantação do ISCED na província. São lembranças boas, somos técnicos superiores, apesar de que não é bom falar no dinheiro, mas foi bom porque o dinheiro aumentou, o salário do técnico superior é diferente do salário do técnico médio, visto que há uma diferença abismal. (José Soma Daniel, 2013).

Essas recordaçóes de situaçóes vivenciadas na academia pelos ex-estudantes do curso de Ciências da Educação, opção Matemática, representaram esforços dos depoentes emrememorar suas experiências e vivências sobre um passado que deixou muitas marcas positivas e negativas.

\section{Considerações finais}

Neste artigo, o nosso objetivo foi focalizar as percepçóes e representaçóes de professores e ex-estudantes do curso de formação de professores de Matemática do Instituto Superior de Ciências da Educação (ISCED) sobre a trajetória e as vivências do curso. Passamos, a seguir, a focalizar o que foi revelado por meio das narrativas. Nas narrativas produzidas sob a metodologia da História Oral, 
os colaboradores da pesquisa evidenciaram aspectos relacionados à criação do curso, às principais dificuldades enfrentadas, às propostas curriculares e a algumas concepçôes sobre o curso.

O curso de Ciências da Educação, opção Matemática, surgiu a partir da criação do ensino superior na província de Cabinda. Nesse contexto, foi criada a Comissão Provincial Instaladora do Ensino Superior em Cabinda (COPIESCA), que trabalhou arduamente em colaboração com o governo da província de Cabinda, até a instalação do Centro Universitário de Cabinda (CUC). O centro começou a funcionar com três núcleos integrados à Universidade Agostinho Neto (UAN), que são: o Instituto Superior de Ciências da Educação (ISCED), a Faculdade de Economia e a Faculdade de Direito. Dos três núcleos, o ISCED tem por objetivo a formação de professores em nível superior para atender as demandas do ensino de base, médio e superior. O núcleo do ISCED teve o seu início com quatro cursos: o de curso de Ciências da Educação, opção História, o de opção Pedagogia, o de opção Psicologia e o de opção Matemática. Este último constituiu nosso objeto de pesquisa e foi criado para dar respostas à demanda da pressão social que a província viveu em termos de professores de Matemática em nível superior.

A formação de professores de Matemática no curso de Ciências da Educação, opção Matemática, ocorreu sob o signo da urgência, da carência e da desigualdade de condiçôes no país (Garnica, 2010, p. 39). Havia carência de professores em quantidade e qualidade; não havia biblioteca para os estudantes realizarem pesquisas, muito menos bibliografias para preparação das aulas; o edifício que o curso ocupava pertencia/pertence a uma instituiçáo de ensino médio. Num primeiro momento, devido à falta de professores, recorreu-se a profissionais provenientes dos ISCEDs de Luanda e do Lubango, posteriormente solicitou-se a ajuda de professores cooperantes cubanos.

A grade curricular usada nos primeiros anos do funcionamento do curso era de cinco anos. Ela foi alterada para quatro anos depois da reforma verificada na UAN. No entanto, tanto o primeiro como o segundo plano curricular priorizavam conteúdos matemáticos, colocando os conhecimentos pedagógicos em segundo plano.

Os primeiros estudantes descreveram vários momentos marcantes sobre suas experiências e vivências no curso, tais como a carência de professores, a incerteza do curso, a vontade de vencer, entre outros aspectos.

Os relatos dos depoimentos contribuíram para maior compreensão dacriação e trajetória do curso. Desse modo, podemos ainda dizer que ouvir a voz dos que vivenciaram a criação e desenvolvimentodo curso nos possibilitou reconstruir uma versão sobre a trajetória da formação de professores de Matemática no curso 
de Ciências da Educação, opção Matemática, do núcleo do Instituto Superior de Ciências da Educação de Luanda em Cabinda.

\section{Referências}

ALBERTI, Verena. Ouvir contar: textos em história oral. Rio de Janeiro: Editora FGV, 2004.

. Manual de História Oral. 3.ed. Rio de Janeiro: Editora FGV, 2005.

ALMEIDA, Dóris Bittencourt. As memórias e a história da educação: aproximaçóes teóricometodológicas. Revista História da Educação, Pelotas, v. 13, n. 27, p. 211-243, jan./abr. 2009. Disponível em: <http://seer.ufrgs.br/index.php/asphe/article/view/29033/pdf>. Acesso em: 28 jan. 2020.

BUISSA, Inês Florinda Luís. Memórias de um curso de formação de professores de Matemática no Instituto Superior de Ciências da Educação de Cabinda/Angola (1998-2009). Tese (Doutorado em Educação) - UFMG, Belo Horizonte, MG, 2016.

DELGADO, Lucilia de Almeida Neves. História oral: memória, tempo, identidades. 2.ed. Belo Horizonte: Autêntica, 2010.

GARNICA, Antonio Vicente Marafioti. Registrar oralidades, analisar narrativas: sobre pressupostos da História Oral em Educação Matemática. Ciências Humanas e Sociais em Revista, Seropédica v. 32, n.2, p. 29-42, jul./dez. 2010.

; SOUZA, Luzia Aparecida de. Elementos de história da EducaçãoMatemática. São Paulo: Cultura Acadêmica, 2012.

SILVA, Eugénio Adolfo Alves da. O burocrático e o político na administração universitária: continuidades e rupturas na gestão dos recursos humanos docentes na Universidade Agostinho Neto (Angola). Tese (Doutorado em Educação Matemática) -Universidade do Minho, Braga/ Portugal, 2004.

THOMSON, Alistair. Aos cinquenta anos: uma perspectiva internacional da história oral. Tradução Paulo Martins Garchet. In: FERREIRA, Marieta de Moraes; FERNANDES, Tania Maria; ALBERTI, Verena (Org.). História oral: desafios para o século XXI. Rio de Janeiro: Editora Fiocruz/Casa de Oswaldo Cruz/CPDOC - Fundação Getúlio Vargas, 2000. p. 47-65.

; FRISCH, Michael; HAMILTON, Paula. Os debates sobre memória e história: alguns aspectos internacionais. In: AMADO, Janaina; FERREIRA, Marieta de Moraes. Usos \& abusos da História Oral. 8. ed. Rio de Janeiro: FGV, 2006. 
THOMPSON, Paul. A voz do passado: História Oral. 2. ed. São Paulo: Paz e Terra, 1998.

UAN - UNIVERSIDADE AGOSTINHO NETO. Discurso de abertura proferido pela Magnífica Reitora Professora Doutora Laurinda Hoygaard. Luanda, 1998.

\section{Fontes orais}

BALENDA, Nlandu. [abr. 2013]. Entrevistadora: Inês Florinda Luís Buissa. Cabinda/ Angola, 7 abr. 2013. Disponível em: <https://repositorio.ufmg.br/handle/1843/BUBDAKBH5P?show=full>. Acesso em: 22 jun. 2020.

BASSANZA, José Antônio. [abr. 2013]. Entrevistadora: Inês Florinda Luís Buissa. Cabinda/Angola, 3 abr. 2013. Disponível em: <https://repositorio.ufmg.br/handle/1843/ BUBD-AKBH5P?show=full>. Acesso em: 22 jun. 2020.

BIFICA, Nicolau. [mai. 2013]. Entrevistadora: Inês Florinda Luís Buissa. Cabinda/ Angola, 27 mai. 2013. Disponível em: <https://repositorio.ufmg.br/handle/1843/ BUBD-AKBH5P?show=full>. Acesso em: 22 jun. 2020.

BUMBA, David Macaia. [abr. 2013]. Entrevistadora: Inês Florinda Luís Buissa. Cabinda/ Angola, 29 abr. 2013. Disponível em: <https://repositorio.ufmg.br/handle/1843/BUBDAKBH5P?show=full>. Acesso em: 22 jun. 2020.

DANIEL, José Soma. [mai. 2013]. Entrevistadora: Inês Florinda Luís Buissa. Cabinda/ Angola, 20 mai. 2013. Disponível em: <https://repositorio.ufmg.br/handle/1843/ BUBD-AKBH5P?show=full>. Acesso em: 22 jun. 2020.

GOMES, Estevão. [mai. 2013]. Entrevistadora: Inês Florinda Luís Buissa. Cabinda/ Angola, 25 mai. 2013. Disponível em: <https://repositorio.ufmg.br/handle/1843/ BUBD-AKBH5P?show=full>. Acesso em: 22 jun. 2020.

KUABI, Faustino Mombo. [2013]. Entrevistadora: Inês Florinda Luís Buissa. Cabinda/ Angola, 5 mai. 2013. Disponível em: <https://repositorio.ufmg.br/handle/1843/BUBDAKBH5P?show=full>. Acesso em: 22 jun. 2020.

MATOMBE, António Teodoro. [mai. 2013]. Entrevistadora: Inês Florinda Luís Buissa. Cabinda/Angola, 29 mai. 2013. Disponível em: <https://repositorio.ufmg.br/ handle/1843/BUBD-AKBH5P?show=full >. Acesso em: 22 jun. 2020.

NZAU, Domingos Kimpolo. [mar. 2013]. Entrevistadora: Inês Florinda Luís Buissa. Cabinda/Angola, 28 mar. 2013. Disponível em: <https://repositorio.ufmg.br/ handle/1843/BUBD-AKBH5P?show=full>. Acesso em: 22 jun. 2020. 
RAMOS, Lucas Raposo. [abr. 2013]. Entrevistadora: Inês Florinda Luís Buissa. Cabinda/ Angola, 5 abr. 2013. Disponível em: <https://repositorio.ufmg.br/handle/1843/BUBDAKBH5P?show=full>. Acesso em: 22 jun. 2020.

Resumo: Este artigo traz à tona os resultados de uma investigaçáo de doutorado que focalizou o período inicial (1998-2009) de um curso de formação de professores de Matemática, oferecido pelo Instituto Superior de Ciências da Educação (ISCED) de Cabinda/Angola. Para além de documentos escritos e monografias, foram usadas narrativas de 10 entrevistas de professores e ex-estudantes, recorrendo à metodologia de História Oral. Em nossas análises, verificamos que a criação do centro que oferecia o curso referenciado ocorreu num momento de grande instabilidade sociopolítica, econômica, educacional e cultural do país, devido ao longo período 27 anos - de guerra civil. Esse contexto repercutiu fortemente no curso durante os primeiros anos de seu funcionamento, caracterizados por dificuldades que se prendiam na carência de docentes, de infraestruturas, de materiais bibliográficos e de equipamentos. As memórias de estudantes e docentes do curso também evidenciaram que a formação de professores de Matemática em nível superior na província de Cabinda ocorreu sob o signo de urgência e da carência, deixando marcas na trajetória profissional dos professores e na formação acadêmica dos ex-estudantes.

Palavras-Chave: Formação de professores. História Oral. História da formação de professores de Matemática. ISCED/Cabinda.

\section{Trajectory of mathematics teacher education in the Higher Institute of Educational Sciences in Cabinda (1998-2009)}

Abstract: This article brings up the results of a doctoral research that focused on the initial period (1998-2009) of a mathematics teacher education course, offered by the Higher Institute of Educational Sciences (ISCED) in Cabinda/Angola. In addition to written documents and monographs, narratives from 10 interviews of professors and former students were used, using the methodology of Oral History. In our analyzes, we found that the creation of the center that offered the referred course, took place at a time of great socio-political, economic, educational and cultural instability in the country, due to the long period -27 years - of civil war. This context had a strong repercussion on the course during the first years of its operation, characterized by difficulties that were linked to the lack of professors, infrastructure, bibliographic materials and equipment. The memories of students and professors of the course also showed that the education of Mathematics teachers at a higher level in the province of Cabinda occurred under the sign of urgency and lack, leaving marks in the professional trajectory of professors and in the academic training of former students.

Keywords: Teacher education. Oral History. History of mathematics teachers. ISCED/Cabinda.

Recebido em 10/03/20

Aprovado em 18/05/20 